\title{
(2) OPEN ACCESS \\ Immunohistochemistry with anti-MAL antibody and RNAscope with MAL probes are complementary techniques for diagnosis of primary mediastinal large B-cell lymphoma
}

\author{
Anthony Jacquier ำ , ${ }^{1}$ Charlotte Syrykh, ${ }^{2}$ Isabelle Bedgedjian, ${ }^{1}$ Franck Monnien, \\ Camille Laurent, ${ }^{2}$ Séverine Valmary-Degano, ${ }^{1}$ Pierre Brousset ${ }^{2}$
}

'Department of Pathology, University Hospital of Besancon, Besancon, France ${ }^{2}$ Department of Pathology, Cancer University Institute of Toulouse, Toulouse, France

\section{Correspondence to} Professor Pierre Brousset, IUCT Oncopole, Toulouse 31100, France; brousset.p@chutoulouse.fr

Received 11 May 2020 Revised 3 July 2020 Accepted 7 July 2020 Published Online First 24 August 2020
Check for updates

(c) Author(s) (or their employer(s)) 2021. Re-use permitted under CC BY-NC. No commercial re-use. See rights and permissions. Published by BMJ.

To cite: Jacquier $A$, Syrykh C, Bedgedjian I, et al. J Clin Pathol

2021:74:396-399.

\section{ABSTRACT}

Aims Primary mediastinal large B-cell lymphoma (PMBL) diagnosis can be challenging on needle biopsies. Robust techniques are needed to ensure diagnosis of this lymphoma which is highly sensitive to recently developed therapy protocols.

Methods In this study, we sought to determine precise PMBL phenotype, compared with diffuse large B-cell lymphoma not otherwise specified, by combining immunohistochemistry with anti-MAL antibody and RNA in situ hybridisation (RNAscope) with specific MAL probes.

Results The overall MAL positivity level reached 93\% (14/15) of cases of PMBL. Among the 15 cases enrolled in the study, 11 were undoubtedly positive for MAL immunostaining whereas 13 were positive by RNA in situ hybridisation. Interestingly, one case that was negative by in situ hybridisation turned out to be positive by immunohistochemistry.

Conclusions Taken together, our results demonstrate that in situ detection of both MAL transcripts and protein are complementary and increase the sensitivity and specificity of PMBL diagnosis.

\section{INTRODUCTION}

Primary mediastinal large B-cell lymphoma (PMBL) is a rare subtype of diffuse large B-cell lymphoma (DLBCL), which accounts for about 2\%-3\% of non-Hodgkin's lymphoma. ${ }^{1}$ It is usually seen in young women with bulky anterosuperior mediastinal mass and local invasion. At progression, the common sites of dissemination are kidney, adrenal gland or central nervous system. ${ }^{2}$ Histopathologically, tumours show a diffuse growth pattern, composed of medium to large cells, with abundant pale cytoplasm, which are typically embedded in an alveolar stroma with various degrees of sclerosis. Lymphoma cells express CD20 intensely. CD30 expression is present in $>80 \%$ of cases but usually weak and heterogeneous. ${ }^{3}$ Almost $70 \%$ of cases express CD23. ${ }^{4}$ A majority of cases are CD15 and Epstein-Barr virus (EBV)-associated RNA negative. ${ }^{5}$ Gene expression profiling has described a distinctive PMBL gene signature compared with other large B-cell lymphoma types. ${ }^{6}$ In current practice, PMBL diagnosis is based on a confrontation of clinical, morphological and immunophenotypic findings. Diagnosis can be challenging, especially on needle biopsies, due to the overlap with systemic DLBCL with secondary mediastinal involvement.

One of the most specific markers of PMBL is MAL gene/protein expression. ${ }^{7} \mathrm{MAL}$ is expressed in a subset of thymic medullary B-cell lymphocytes and mature T cells. ${ }^{8}$ MAL protein expression can be identified routinely by immunohistochemistry (IHC) with a commercially available MAL antibody (E1 clone, Santa Cruz). ${ }^{9}$ However, immunohistochemical detection of MAL can be problematic because of instability of certain antibodies and/or lack of sensitivity of this test. RNAscope is a recent RNA in situ hybridisation (RNA ISH) method for formalin-fixed paraffin-embedded (FFPE) tissues, which represents a robust alternative to immunohistochemical techniques in case of absence of reliable antibodies. The aim of our study was to determine precise PMBL phenotype by combining MAL IHC and chromogenic RNA ISH (RNAscope).

\section{MATERIALS AND METHODS}

This study screened 24 patients with PMBL diagnosis from the archives of two French University hospitals (Toulouse and Besançon) between January 2011 and June 2017. Tissue samples were provided by the biobank BB-0033-00024 'Franche-Comté Regional Tumour bank (FCRT)' for Besançon. FFPE tumour samples, in the form of CT-guided biopsies or surgical biopsies, were available for 15 patients. Nine cases were retrieved from the pathology laboratory of the Toulouse Cancer University Institute and six cases from the university hospital of Besançon. These tissue samples were compared with 66 cases of DLBCL not otherwise specified (NOS) retrieved from the same sources. All PMBL cases were evaluated on representative whole tissue sections. DLBCL cases were evaluated on tissue microarrays (TMAs) composed of three cores $(1.5 \mathrm{~mm})$ per cases. Morphological findings were obtained using HES stains. CD23, CD30 immunostainings and EBV-encoded RNA (EBER) chromogenic ISH were studied at diagnosis and not repeated in this study. Three $\mu \mathrm{m}$ tissue sections were used for MAL IHC and RNA ISH. MAL IHC was performed on an automated immunostainer (Dako Autostainer; Dako Colorado) using EnvisionFlex detection (\#K8000; Dako Omnis) with a 9.0 pH EDTA-based buffer (EnvisionFlex TRS High 
pH, \#K8004). MAL antibody (clone E-1, \#sc-390687; Santa Cruz Biotechnology, Dallas, Texas, USA) staining was performed using a 1:100 dilution for $15 \mathrm{~min}$ at room temperature after 5 min peroxidase inhibition by a specific blocking reagent. A few cases and controls were checked on a Bond Max immunostainer (Leica) according to the protocol described by Gentry et al. ${ }^{9}$ The quality and reproducibility of the staining turned out to be similar with the two systems.

In situ detection of $M A L$ transcripts was performed with RNAscope 2.5 Assay for Ventana Discovery Ultra system (Advanced Cell Diagnostics, Hayward, California, USA) using RNAscope 2.5 vs Reagent kit-BROWN (\#322200, ACD Bio). MAL probes (RNAscope 2.5 vs probe Hs-MAL, ACD Bio, \#433319) were incubated with a $6.0 \mathrm{pH}$ citrate-based buffer (RNAscope 2.5 vs Target Retrieval, \#322221) maintained at a $97^{\circ} \mathrm{C}$ for $32 \mathrm{~min}$ and treated with protease (RNAscope 2.5 vs mRNA pretreat 3-Protease, \#322218) at $37^{\circ} \mathrm{C}$ for $16 \mathrm{~min}$. $M A L$ probes were hybridised for $60 \mathrm{~min}$. To ensure results interpretability, positive control probe (RNAscope 2.5 vs PPIB \#313909) and negative control probe (RNAscope 2.5 vs DapB \#312039) were used.

FFPE benign tonsil tissues were used as control for MAL immunostaining and MAL RNAscope. Both techniques were concordant and showed cytoplasmic MAL protein/gene expression in a subset of interfollicular $\mathrm{T}$ cells, nerves, endothelial cells and squamous epithelium (figure 1). In lymphoma tissue samples, MAL immunoreactivity/signal of T-cell lymphocytes served as an internal control. IHC for MAL was considered positive if cytoplasmic staining was shown in $>10 \%$ of tumour cells. ${ }^{9}$ Immunostaining was graded according to level of intensity: $1+=$ weak was light/pal brown, $2+=$ moderate was light brown and $3+=$ strong was dark brown). RNAscope $M A L$ analysis was also considered positive according to the threshold of $10 \%$ of tumour cells. MAL RNA expression was scored according to semi-quantitative Advanced Cell Diagnostics (ACD) scoring system. Score $0=$ no staining or $<1 \mathrm{dot} / 10$ cells, score $1+=1-3$ dots/cell, score $2+=4-9$ dots/cell and none or very few dot clusters, score $3+=10-15$ dots/cell and/or $<10 \%$ dots are in clusters, score $4+=>15$ dots/cell and/or $>10 \%$ dots are in clusters. The tumour cell surface staining was evaluated by counting 100 contiguous tumour cells.

\section{RESULTS}

\section{PMBL and DLBCL characterisation}

Fifteen cases of PMBL and 66 cases of DLBCL NOS were evaluated for MAL protein/gene expression. Among the 15 cases of PMBL enrolled, 8 patients were female and 7 patients were male, with ages ranging from 21 to 50 (median $=30$ ) years. One tissue sample came from biopsies by mediastinoscopy, others corresponded to needle biopsies. Crush artefacts on HES examination were frequent in microbiopsies. All cases strongly expressed CD20, 9/15 (60\%) cases showed a weak and at least focal staining for CD30, 11/15 (73\%) cases expressed CD23 (table 1). None of the 12 PMBL cases tested with EBER at diagnostic were positive. The characteristics of our cohort of PMBL cases roughly match with those of other series. ${ }^{9}{ }^{10}$ The 66 cases of DLBCL NOS consisted of 24 females and 42 males and ranged on age from 17 to 98 (median $=72$ ) years. The DLBCL NOS were composed of a mixture of germinal centre B-cell and non-germinal centre B-cell phenotype (table 1). All cases expressed CD20. Forty-nine DLBCL NOS cases were nodal. Among the 17 extranodal cases, 1 case was from kidney involvement and 1 from lung involvement. Other extranodal

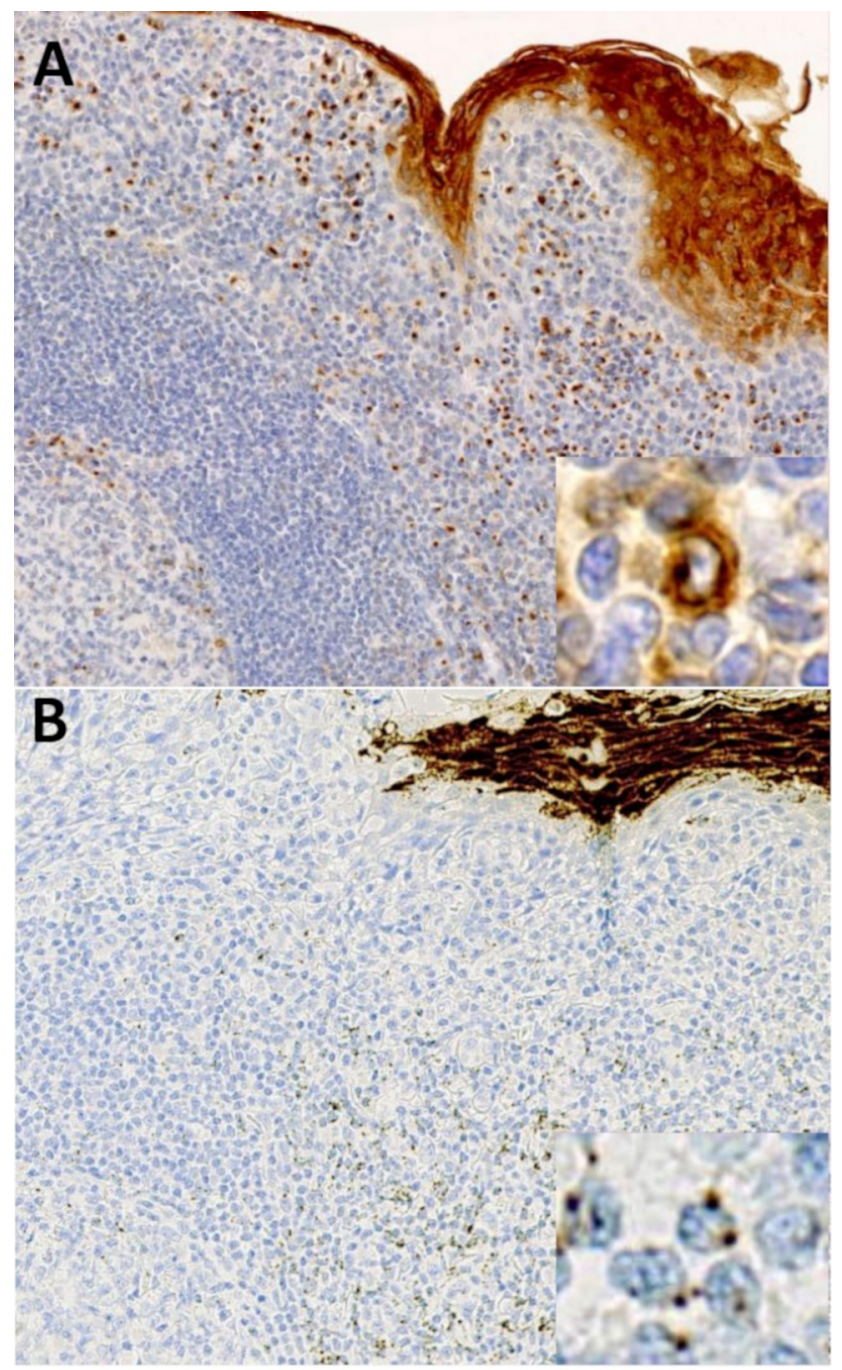

Figure 1 (A) Control for immunohistochemistry with MAL antibody in benign tonsil tissue. The pattern is predominantly cytoplasmic, weak to moderate in interfollicular T cells, with frequently Golgi zone accentuation. Note the intense reactivity seen in squamous epithelium. (B) Control for RNAscope with MAL probes in benign tonsil tissue. MAL transcripts appear as perinuclear dots, with a few number of copies in interfollicular T cells. More than 15 dots/cell was seen in squamous epithelium.

cases were from the spleen, testis, maxillary sinus or digestive tract.

\section{MAL staining in PMBL and DLBCL}

MAL protein was expressed in 11/15 (73\%) cases of PMBL and 0/66 (0\%) cases of DLBCL NOS (table 1). The staining was cytoplasmic, membranous and/or punctate perinuclear (figure 2A,B). All positive cases of PMBL had $>30 \%$ positive tumour cells, $5 / 11$ cases showed a weak staining and 4/11 a moderate staining. Only two cases showed a strong expression of MAL protein. Four cases of PMBL were negative. The overall sensitivity and specificity for MAL staining in distinguishing PMBL from DLBCL NOS was of $73 \%$.

$M A L$ mRNA transcripts were detectable in $13 / 15(86 \%)$ cases of PMBL and 1/66 cases of DLBCL NOS. The various number of $M A L$ mRNA molecules was visualised in the form of variable number of perinuclear dots (figure $2 \mathrm{~A}, \mathrm{C}$ ). Among the 13 positive PMBL cases, $6(46 \%)$ cases were scored $1+, 5$ (38\%) cases were 
Table 1 Clinical and phenotypic characterisation of cases of PMBL and DLBCL NOS

\begin{tabular}{lll}
\hline & PMBL & DLBCL NOS \\
\hline Median age (range) & $30(21-50)$ & $72(17-98)$ \\
Sex ratio (male/female) & $7 / 8$ & $42 / 24$ \\
CD20 (positive/total cases) (\%) & $15 / 15(100)$ & $66 / 66(100)$ \\
CD10 (positive/total cases) (\%) & $6 / 14(42)$ & $15 / 56(26)$ \\
BCL6 (positive/total cases) (\%) & $13 / 14(92)$ & $27 / 37(72)$ \\
MUM1 (positive/total cases) (\%) & $6 / 14(42)$ & $30 / 41(73)$ \\
MAL immunohistochemistry (positive/total cases) (\%) & $11 / 15(73)$ & $0 / 66(0)$ \\
MAL RNA scope (positive/total cases) (\%) & $13 / 15(86)$ & $1 / 66(1.5)$ \\
\hline
\end{tabular}

DLBCL NOS, diffuse large B-cell lymphoma not otherwise specified; PMBL, primary mediastinal B-cell lymphoma.

scored $2+$ and $2(16 \%)$ cases were scored $3+$, according to ACD scoring system. None of cases were scored $4+$. One case was negative. One case was not reliably interpretable and considered negative (see details below). The overall sensitivity and specificity for MAL RNAscope in distinguishing PMBL from DLBCL NOS was $86 \%$ and $98.5 \%$, respectively.

In one case of DLBCL NOS, RNAscope showed a moderate $2+$ level of expression of $M A L$ mRNA while IHC was negative (figure 2D-F). This case corresponded to a man aged 49 years who presented multiple cervical lymphadenopathies associated with lung invasion at diagnostic. Mediastinal involvement was not clearly described. Microscopically, HES pictures showed an usual aspect of DLBCL without specific stromal changes.
Table 2 MAL phenotype of PMBL cases combining IHC and RNAscope

\begin{tabular}{lllll}
\hline & $\begin{array}{l}\text { MAL IHCI } \\
\text { RNAscope } \\
\text { double } \\
\text { positivity }\end{array}$ & $\begin{array}{l}\text { MAL RNAscope } \\
\text { positivity only }\end{array}$ & $\begin{array}{l}\text { MAL IHC } \\
\text { positivity } \\
\text { only }\end{array}$ & $\begin{array}{l}\text { MAL } \\
\text { negative }\end{array}$ \\
\hline $\begin{array}{l}\text { PMBL cases } \\
\text { (positive/total } \\
\text { cases) }(\%)\end{array}$ & $10 / 15(66)$ & $3 / 15(20)$ & $1 / 15(7)$ & $1 / 15(7)$ \\
\hline
\end{tabular}

IHC, immunohistochemistry; PMBL, primary mediastinal B-cell lymphoma.

\section{Combined MAL gene/protein analysis, PMBL}

Combining IHC and RNAscope analyses, 14/15 (93\%) cases of PMBL were MAL positive (table 2). Out of 15, 10 (66\%) cases of PMBL showed both expression of MAL gene/protein, with a relative agreement between the intensity of the immunostaining and the number of copies of $M A L$ mRNA molecules. Three cases of PMBL were only positive for RNAscope. Two of these three MAL IHC-negative cases displayed a low number of MAL mRNA copies. They were scored $1+$ in $26 \%$ and $31 \%$ of the tumour cells, respectively. The third case showed a relatively high number of copies of MAL mRNA, scored 2+ according to ACD scoring system for $62 \%$ of the tumour cells.

Two cases of PMBL were considered negative for RNAscope. In the first, it was not possible to determine the origin of the cellular signals, either from tumorous cells or from reactive $\mathrm{T}$ cells. Crush artefacts made morphological analysis difficult. Interestingly, IHC analysis was more informative. Enough cells

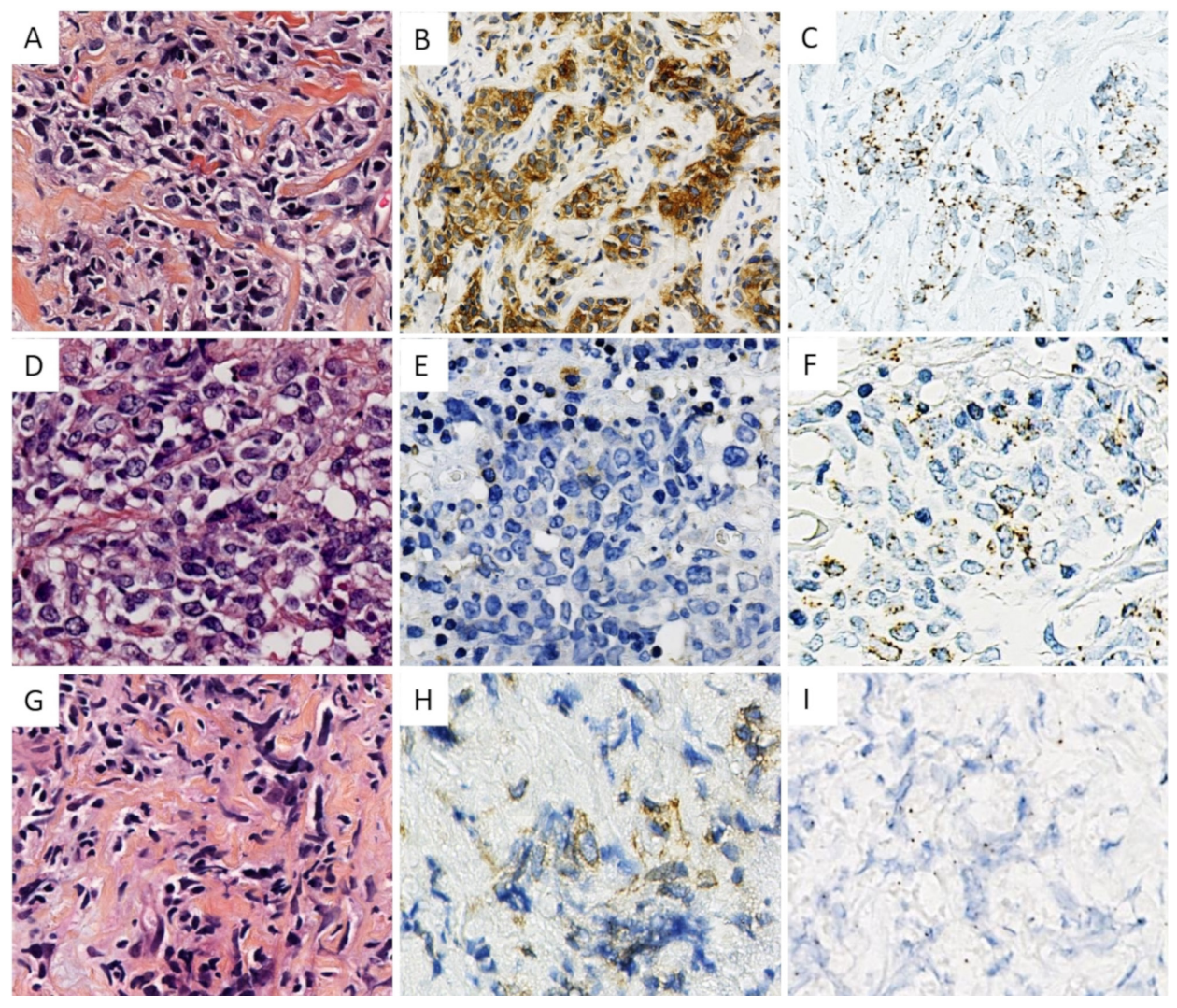

Figure 2 (A-C) HES MAL IHC and MAL RNAscope of a representative case of PMBL. (D-F) HES MAL IHC and MAL RNAscope of the case diagnosed as DLBCL NOS in cervical lymph node for patient with pulmonary involvement. Note the absence of stromal component in HES. (G-I) HES, MAL IHC and MAL RNAscope of the positive case for IHC and non-contributive for RNAscope. DLBCL NOS, diffuse large B-cell lymphoma not otherwise specified; IHC, immunohistochemistry; PMBL, Primary mediastinal large B-cell lymphoma. 
showed an interpretable cytoplasmic/membranous staining (figure 2G-I). The second RNAscope negative case did not show protein expression. Combining MAL IHC and RNAscope, the sensitivity to distinguish PMBL from DLBCL NOS was 93\%.

\section{DISCUSSION}

PMBL represents a distinct clinicopathological entity for which the diagnosis could be challenging on needle biopsies, especially in cases with atypical clinical presentation or extra mediastinal involvement. ${ }^{11}$ In our work, we have shown that combining MAL IHC and MAL RNA ISH is an excellent method for determining precise PMBL phenotype. MAL gene or protein expression was visualised in $93 \%$ of cases of PMBL with the combination of these two techniques. The sensitivity and specificity reported for MAL IHC ranged between 58\%-72\% and 97\%-100\%, respectively, with series of $12-43$ cases. $^{78} 12$ In our study, we used the commercially available antibody with our routine IHC technique. Our results were very similar in terms of sensitivity and reproducibility to those previously described by Gentry et al. ${ }^{9}$ Similarly, we observed that this anti-MAL antibody, even tested in optimal conditions, missed around 25\% of the PMBL cases while requiring rigorous conditions for immunohistochemical techniques.

One important finding of our study is that MAL RNA ISH allowed to determine the PMBL phenotype of three cases which were negative for IHC. Other studies demonstrated the utility of RNA ISH for identifying phenotypic or prognostic markers in DLBCL. ${ }^{13-16}$ This highly sensitive technology is able to target partially degraded RNAs of $<50$ base pairs. ${ }^{17}$ RT-PCR-based technologies were initially reserved for frozen tissue, they are now usable in FFPE tissues. Two studies reported molecular classification assays for the distinction of PMBL from DLBCL subtypes based on gene expression profiles. ${ }^{18} 19$ These classifiers simultaneously evaluated the expression of 21 or 58 genes. They demonstrated a very high reproducibility and reported about $10 \%$ of uncertain or unclassifiable cases. These unclassifiable cases underline the usefulness of confrontation with morphological analysis. RNA ISH allows analysis of RNA expression while also preserving tissue architecture and mapping the observed signals to individual cells. Determining the cellular source of RNA could be useful, especially with biomarkers such as $M A L$ which are expressed both in tumour and non-tumour cells. However, as shown in our cohort, it requires high-quality tissue material without crush artefacts. In addition, RNA ISH is much faster compared with global molecular techniques such as quantitative RT-PCR with comparable cost (€100/case).

Taken together, the results of our study clearly demonstrate that in situ detection of both $M A L$ transcripts and protein are complementary and increase the sensitivity and specificity of PMBL diagnosis. Identifying PMBL with specific markers becomes critical given the emergence of novel therapeutic approaches. ${ }^{20}$ Combining RNA HIS and IHC could be a useful tool to identify numerous other biomarkers on FFPE tissue samples with a morphological context. These techniques are simple, reproducible and thus compatible with routine practice.

\section{Handling editor Mary Frances McMullin.}

Contributors PB had full access to all the data in the study and takes responsibility for the integrity of the data and the accuracy of the data analysis. Study concept and design: AJ, CS, SV-D, CL, PB. Analysis and interpretation of data: AJ, CS, IB, FM, CL, $\mathrm{PB}$.
Funding Supported by grants from the French National Agency of Research (ANR) through the Labex TOUCAN.

Competing interests None declared.

Patient consent for publication Not required.

Provenance and peer review Not commissioned; externally peer reviewed.

Open access This is an open access article distributed in accordance with the Creative Commons Attribution Non Commercial (CC BY-NC 4.0) license, which permits others to distribute, remix, adapt, build upon this work non-commercially, and license their derivative works on different terms, provided the original work is properly cited, appropriate credit is given, any changes made indicated, and the use is non-commercial. See: http://creativecommons.org/licenses/by-nc/4.0/.

\section{ORCID iD}

Anthony Jacquier http://orcid.org/0000-0002-8326-6212

\section{REFERENCES}

1 Swerdlow SH, Campo E, Pileri SA, et al. The 2016 revision of the World Health Organization classification of lymphoid neoplasms. Blood 2016;127:2375-90.

2 Lazzarino M, Orlandi E, Paulli M, et al. Treatment outcome and prognostic factors for primary mediastinal (thymic) B-cell lymphoma: a multicenter study of 106 patients. J Clin Oncol 1997:15:1646-53.

3 Higgins JP, Warnke RA. CD30 expression is common in mediastinal large B-cell lymphoma. Am J Clin Pathol 1999;112:241-7.

4 Calaminici M, Piper K, Lee AM, et al. CD23 expression in mediastinal large B-cell lymphomas. Histopathology 2004;45:619-24.

5 Cazals-Hatem D, Lepage E, Brice P, et al. Primary mediastinal large B-cell lymphoma. A clinicopathologic study of 141 cases compared with 916 nonmediastinal large B-cell lymphomas, a GELA ("Groupe d'Etude des Lymphomes de l'Adulte") study. Am J Surg Pathol 1996;20:877-88.

6 Rosenwald A, Wright G, Leroy K, et al. Molecular diagnosis of primary mediastinal $B$ cell lymphoma identifies a clinically favorable subgroup of diffuse large B cell lymphoma related to Hodgkin lymphoma. J Exp Med 2003;198:851-62.

7 Copie-Bergman C, Gaulard P, Maouche-Chrétien L, et al. The MAL gene is expressed in primary mediastinal large B-cell lymphoma. Blood 1999;94:3567-75.

8 Copie-Bergman C, Plonquet A, Alonso MA, et al. MAL expression in lymphoid cells: further evidence for mal as a distinct molecular marker of primary mediastinal large B-cell lymphomas. Mod Pathol 2002;15:1172-80.

9 Gentry M, Bodo J, Durkin L, et al. Performance of a commercially available MAL antibody in the diagnosis of primary mediastinal large B-cell lymphoma. Am J Surg Pathol 2017;41:189-94.

10 Bledsoe JR, Redd RA, Hasserjian RP, et al. The immunophenotypic spectrum of primary mediastinal large B-cell lymphoma reveals prognostic biomarkers associated with outcome. Am J Hematol 2016;91:E436-41.

11 Yuan J, Wright G, Rosenwald A, et al. Identification of primary mediastinal large B-cell lymphoma at Nonmediastinal sites by gene expression profiling. Am J Surg Pathol 2015;39:1322-30.

12 Dorfman DM, Shahsafaei A, Alonso MA. Utility of CD200 immunostaining in the diagnosis of primary mediastinal large B cell lymphoma: comparison with MAL, CD23, and other markers. Mod Pathol 2012;25:1637-43.

13 Sun C, Jia Y, Wang W, et al. Integrative analysis of PD-L1 DNA status, mRNA status and protein status, and their clinicopathological correlation, in diffuse large B-cell lymphoma. Histopathology 2019;74:618-28.

14 Son S-M, Ha S-Y, Yoo H-Y, et al. Prognostic impact of MYC protein expression in central nervous system diffuse large B-cell lymphoma: comparison with MYC rearrangement and MYC mRNA expression. Mod Pathol 2017;30:4-14.

15 Wang Z, Cook JR. PDCD1LG2 (PD-L2) RNA in situ hybridization is a sensitive, specific, and practical marker of primary mediastinal large B-cell lymphoma. Br J Haematol 2018;181:564-6.

16 Federmann B, Frauenfeld L, Pertsch $\mathrm{H}$, et al. Highly sensitive and specific in situ hybridization assay for quantification of SOX11 mRNA in mantle cell lymphoma reveals association of TP53 mutations with negative and low SOX11 expression. Haematologica 2020;105:754-64.

17 Wang F, Flanagan J, Su N, et al. RNAscope: a novel in situ RNA analysis platform for formalin-fixed, paraffin-embedded tissues. J Mol Diagn 2012;14:22-9.

18 Bobée V, Ruminy P, Marchand V, et al. Determination of molecular subtypes of diffuse large B-cell lymphoma using a reverse transcriptase multiplex ligation-dependent probe amplification classifier: a CALYM study. J Mol Diagn 2017;19:892-904.

19 Mottok A, Wright G, Rosenwald A, et al. Molecular classification of primary mediastinal large B-cell lymphoma using routinely available tissue specimens. Blood 2018:132:2401-5.

20 Armand P, Rodig S, Melnichenko V, et al. Pembrolizumab in relapsed or refractory primary mediastinal large B-cell lymphoma. J Clin Oncol 2019;37:3291-9. 